\title{
Determinants of exclusive consumption of fluoride-free water: a cross-sectional household study in rural Ethiopia
}

\author{
Alexandra C. Huber • Sarah Bhend • \\ Hans-Joachim Mosler
}

Received: 16 June 2011 / Accepted: 31 August 2011 / Published online: 18 September 2011

(C) Springer-Verlag 2011

\begin{abstract}
Aim The occurrence of high fluoride concentrations in the ground- and surface water all over the world leads to the risk of developing dental and skeletal fluorosis. In Ethiopia, 8 million people depend on water sources with excessive fluoride. In four project areas in the Ethiopian Rift Valley, fluoride removal household filters based on bone char media have been implemented. This study examines possible predictors of consuming filtered water derived from various behavior change theories.

Subject and methods In a complete cross-sectional survey, 160 filter users were interviewed through structured face-toface interviews. A logistic regression was carried out to reveal factors predicting consumption of filtered water.

Results The results show that the consumption of fluoridefree water is mainly related to people's pride in offering filtered water to guests (status norm) and the feeling of being able to produce enough water with the filter (perceived behavioral control). Moreover, the study showed that the more filter users like the taste of filtered water and the more expensive they perceive the filter media, the more likely users will exclusively consume filtered water (attitudinal beliefs). Furthermore, perceiving the act of filling as a matter of habit (perceived habit) enhances filtered water consumption.
\end{abstract}

\footnotetext{
A. C. Huber $(\varangle) \cdot$ H.-J. Mosler

Eawag: Swiss Federal Institute of Aquatic

Science and Technology,

Ueberlandstrasse 133, P.O. Box 611, 8600 Duebendorf, Switzerland

e-mail: alexandra.huber@eawag.ch

S. Bhend

Department of Psychology, Division of Social Psychology, University of Zurich,

Binzmuehlestrasse 14, P.O. Box 15, 8050 Zurich, Switzerland
}

Conclusion Based on the results, possible intervention strategies to change the influential psychological factors and, hence, increase the consumption of treated water can be designed.

Keywords Fluoride removal filter Behavior change . Status norm $\cdot$ Perceived behavior control $\cdot$ Attitudinal beliefs $\cdot$ Habit

\section{Introduction}

Approximately 200 million people worldwide rely on water sources contaminated with excessive fluoride. The probability of occurrence of high fluoride concentration in ground- and surface water was detected in various countries such as India, China, Argentina, Mexico, and in several African countries (Amini et al. 2008). In Ethiopia, especially in the Ethiopian Rift Valley, water contaminated with fluoride has led to a serious public health problems (Kloos and Tekle-Haimanot 1999; Tekle-Haimanot 2005; Tekle-Haimanot et al. 2006).

Fluoride is mostly absorbed into the human body by drinking or cooking with water containing fluoride (TekleHaimanot et al. 2006). Excess fluoride intake can cause dental and skeletal fluorosis. Symptoms range from irregular brown patches on teeth to deformation of bones, limitation of joint movements, and even crippling (crippling fluorosis) in the last stage of the disease, accompanied by serious psychosocial impacts (Tekle-Haimanot 2005).

Out of a population of 10 million in the Ethiopian Rift Valley, 8.5 million people are exposed to high fluoride contamination (Tekle-Haimanot 2005). Medical treatment of the disease has been found to be difficult and mostly 
ineffective. Therefore, preventing high fluoride consumption becomes crucial.

Bone char filtration is an efficient, simple, and low-cost defluoridation technique, applicable at the household and community levels in semiarid rural areas lacking alternative water sources such as rainwater harvesting or piped water supplies. The filter material is charred animal bone that adsorbs fluoride (Kloos and Tekle-Haimanot 1999; TekleHaimanot 2005). Even though considerable achievements have been made in fluoride mitigation since the problem was first detected in urban areas, fluoride is still not removed effectively. In rural areas, the case is even worse, since only a few filter systems have been installed, and they are not sustained, mostly due to a lack of support and maintenance (Tekle-Haimanot 2005). Except for research on the medical consequences of fluoride (e.g., Malde et al. 2011; Wondwossen et al. 2006), little research has been conducted so far on the topic. As a result, the social, situational, and psychological determinants and consequences of filter use have remained unclear. Leading people to use safe water options implies more than just implementing new technologies; considering and analyzing the social, situational, and psychological factors of using a new technology are crucial. Studies focusing on the social and psychological aspects related to acceptance of bone char filtration as well as the identification of important factors that encourage the use of household filters have not yet been carried out. After implementing new filter technologies, revealing the factors that are important at the beginning of filter use, i.e. the uptake of a new behavior, is of particular interest. A clearer understanding of these determinants enables behavioral-change interventions to be planned to promote filter use and consumption of fluoridetreated water.

\section{Determinants of behavior change}

Various prominent models of behavior change provide a multitude of constructs to identify the key determinants of health behaviors. This study focuses on several contentrelated key determinants of health behavior without following a specific theory. Various constructs are included that are assumed to play an important role. The focus lies on five different beliefs: risk beliefs, attitudinal beliefs, normative beliefs, ability beliefs, and maintenance beliefs. The description of the five beliefs and their determinants can be found in Table 1.

The main purpose of the present field study is to test the social and psychological determinants of the consumption of fluoride-free water to assess valuable implications for specific intervention contents. The results of this survey shall identify enhancing and hindering factors of filter use and further provide knowledge about how to successfully implement new filter technologies and how to persuade people to sustainably use the technologies.

\section{Methods}

To evaluate possible determinants to increase the consumption of fluoride-free water, a cross-sectional survey was employed. After a pilot project in 2007, in April 2010, the project was continued with the distribution of 200 fluoride removal household filters. The filter design consists of a two-bucket system, with a smaller $(10 \mathrm{~L})$ bucket on top containing $2 \mathrm{~L}$ of sand for turbidity removal and a lower bucket $(30 \mathrm{~L})$ containing bone char and calcium phosphate pellets as filter media for fluoride removal. One filling of $8 \mathrm{~L}$ of water can be filtered within half an hour. The sand in the upper bucket needs to be washed from time to time. Depending on the fluoride content of the raw water and the frequency of filter use, the filter media must be exchanged after approximately 1 year to ensure defluoridation effectiveness. The total filter cost is approximately 38 US dollars ( $\$ 14$ for the media, $\$ 24$ for the hardware). Before the distribution, people were informed that they will have to pay $10 \%$ of the initial price and agree to pay $50 \%$ for the filter media when the filter needs refilling. Also prior to the distribution, the local NGO tried to find out together with the village leaders and the community facilitators, how many households are interested in purchasing a filter. In the end, four villages were selected to benefit from the 200 filters. For the distribution of the filters, villagers gathered around the market place to collect their filter buckets and fill them with the bone char. Before receiving the filters, the NGO's social worker and the research assistant gave information about fluoride and fluorosis, as well as clarifying how to operate and maintain the filter.

\section{Study areas}

The filters were distributed in four different villages, Seriti (approximately 200 households), Gura, Chalaleki 1, and Chalaleki 2 (with approximately 100 households each) close to Lake Ziway. The project areas were selected by the local NGO Oromia Self Help Organization (OSHO) and the research team based on fluoride concentration levels, accessibility, and the permission of regional leaders. All of the project areas, rural villages with low-income families, are located in the northern part of the Ethiopian Rift Valley. The villagers, mostly self-sustaining farmers, live basically in little houses built of wood, earth, tin, cement, or concrete and their infrastructure is quite simple (no electricity, sanitation, or fluent water). Usually, people fetch water at a public water source such as a borehole. The 
Table 1 Description of beliefs and their determinants for behavior change

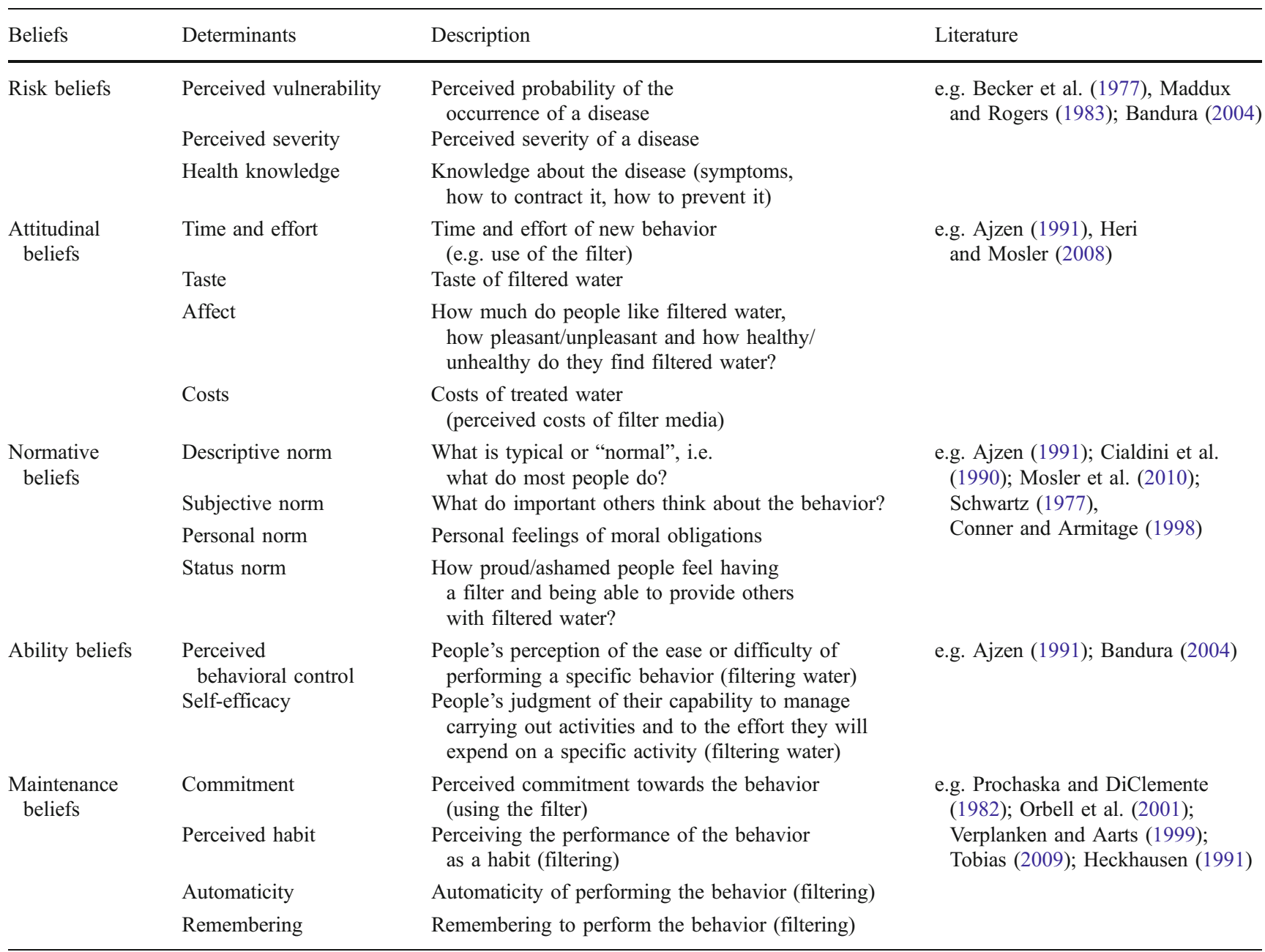

fluoride content of the water sources in the project are have been measured at $2-18 \mathrm{mg} / \mathrm{L}$. These fluoride levels partially exceed the World Health Organization (WHO) guideline value of $1.5 \mathrm{mg} / \mathrm{L}$ (Tekle-Haimanot et al. 2006).

\section{Sample and procedures}

The study design was a complete survey of all filter beneficiaries in the project areas (200 households). Filter users who received a filter in April 2010 were interviewed approximately 2 weeks after distribution of the filter. In this baseline survey, all filter users consented to being interviewed. Because of inclement weather, 40 households in one remote village (Seriti) were not accessible and therefore could not be interviewed.

Because of high illiteracy, the data collection was carried out through structured face-to-face interviews by a team of 10 local college students. Before the survey, the interviewer team attended a workshop learning all about fluoride, fluorosis, and defluoridation, and interviewing techniques (e.g. how to approach a household, how to avoid asking suggestive questions, how to deal with negative reactions). During the investigation, the team was supervised by researchers and field assistants. If possible, the interviews were held with persons responsible for drinking water in the respective household.

\section{Questionnaire and measures}

The structured questionnaire was translated by the local field manager and social worker from English into two local languages (Amharic and Oromic) and revised by the interviewers during the workshop. The applicability of the questionnaire was verified in a pretest (20 households). During the pretest the research team examined the interviewers in order to validate important measures (e.g. estimation of content of jerrycans or cups). The questionnaire was designed to cover various factors of interest underlying the filter use and the consumption of filtered water, including mainly quantitative variables. In general, 
the quantitative bipolar variables were measured on a 9point Likert-scale; for the unipolar variables, a 5-point Likert-scale was used. After data collection, principal factor analysis with varimax rotation and reliability analysisCronbach's alpha $(\alpha)$-were executed with SPSS 17.

Consumption of fluoride-free water The dependent variable for the current consumption of filtered water was quantified in terms of the percentage of drinking filtered water and cooking with filtered water. Participants were asked to show the interviewer a regular cup and to assess how many of these cups the entire family drank per day and used for cooking per day. With the interviewer's estimation of the content of the cup, the total liters consumed per day could be calculated. Afterwards, people were asked how many cups of filtered water the participants used for consumption. The percentage of filtered water consumption compared to total consumption was calculated. From this calculation, two consumption types were extracted: households that consume only filtered water $(100 \%$ of filtered water consumption) and households that still consume untreated water in addition to filtered water (less than $100 \%$ filtered water consumption).

Behavior determinants The questionnaire included items concerning risk beliefs, which was covered by the perceived vulnerability and perceived severity of dental and skeletal fluorosis (e.g., Orbell et al. 2009). Moreover, health knowledge about fluoride and fluorosis was measured with Kprim styled multiple-choice questions (Krebs 2002), a method used if several elements influence an issue. To each aforementioned question (one example is illustrated in Table 2), four responses were developed based on open responses from the pilot survey. For each response, the participants had to decide whether it was correct or not. For four correct ratings of one question, participants received one point; for three correct ratings half a point. Finally, the points were tallied up. Krebs (2002) justifies the scoring system (zero points if more than one answer is wrong) by pointing out that different elements of one question should be known in order to have knowledge about an issue.

Furthermore, questions regarding attitudinal beliefs such as time and effort, and perceived taste were elevated, as well as affective beliefs about health and whether or not the activity itself is agreeable (cf. Table 2). The descriptive norm was covered following Smith et al. (2008), the subjective norm following Park and Smith (2007) and Armitage (2005), and the personal norm is according to Harland et al. (2007). Perceived behavior control was assessed in terms of having enough filtered water available for consumption (see Table 2). Self-efficacy was measured in reference to Armitage (2005). Maintenance belief items were defined as shown in Table 2 (e.g., Orbell et al. 2001).

\section{Results}

In $78.8 \%$ of the cases, the interviewed person was female. According to the participant's preference, the interviews were conducted in Amharic (20.6\%) or Oromic (79.4\%). The majority of participants were Ethiopian Orthodox (95\%). The average age of the respondents was 33.1 years $(\mathrm{SD}=10.6, N=149)$. On average, the interviewees had attended school for 1.5 years $(\mathrm{SD}=2.2, n=159 ; 61.6 \%$ of the participants did not go to school at all). The mean number of people living in one household was six people (range: 1-16 people).

Out of the total sample $(N=160), 79.6 \%$ of the filter users stated they drank and cooked exclusively with filtered water. Of those who still consumed certain amounts of raw water, only $6.9 \%$ indicated they exclusively drank unfiltered water, while $21.9 \%$ stated they cooked with raw water. The filter was filled on average 2.65 times per day $(\mathrm{SD}=1.25)$, mostly when it was completely empty $(43.1 \%)$. The means and standard deviations of the observed variables regarding filter use and determinants of filter use are shown in Table 3.

The mean, in reference to perceived vulnerability, indicates that filter users estimated their likelihood of contracting fluorosis as neither low nor high. Means regarding the perceived severity of dental and skeletal fluorosis (see Table 3) indicate that the impact of dental and skeletal fluorosis was considered severe up to very severe. Regarding health knowledge, the means show that filter owners have a moderate knowledge of fluoride and fluorosis.

The high values of the attitudinal beliefs such as time and effort, taste, and affective belief, indicate that in general people evaluate the filter and filtered water as very positive. As shown in Table 3, the costs for a refill of the filter media is on average considered valid. On average, filtering the water was not perceived as time-consuming or requiring much effort.

The descriptive norm shows a moderate mean. The values concerning the subjective and personal norms (compare Table 3) indicate that the perceived expectations of the social network regarding filter use was considered high, and in general, significant others approved the use of the filter. Furthermore, filter users were proud to offer filtered water to guests.

The filter capacity with a mean of 2.81 and a relatively high standard deviation (see Table 3 ) indicates that there are users who perceived themselves as not being able to produce enough filtered water for the whole family, though users in general saw themselves as being capable of using the filter regularly (compare Table 3).

People seemed to feel deeply committed to using the filter. Furthermore, they perceived the filling of the filter as 
Table 2 Items used for calculation

\begin{tabular}{|c|c|c|c|}
\hline Scale/construct & Example items & Lowest value & Highest value \\
\hline Vulnerability & $\begin{array}{l}\text { How high or low do you feel are the chances that } \\
\text { someone of your family develops skeletal } \\
\text { fluorosis? The chances are... }\end{array}$ & $\begin{array}{l}-2=\text { much lower } \\
\text { than average }\end{array}$ & $\begin{array}{l}2=\text { much higher } \\
\text { than average }\end{array}$ \\
\hline Severity & $\begin{array}{l}\text { Imagine that you contracted dental/skeletal } \\
\text { fluorosis, how severe would be the impact } \\
\text { on your life in general? }\end{array}$ & $0=$ not severe at all & $4=$ very severe \\
\hline \multirow[t]{5}{*}{ Health knowledge } & How can you prevent getting fluorosis? & $\begin{array}{l}4 \text { multiple choice } \\
\text { answers, for each: }\end{array}$ & \\
\hline & By boiling the water before consuming it & $0=$ answer was wrong & \\
\hline & By filtering the water before consuming it. & $1=$ answer was right & \\
\hline & By taking medicine & & \\
\hline & By brushing your teeth more often & & \\
\hline Time and effort & Do you think using the filter takes a lot of effort? & $\begin{array}{l}0=\text { does not take } \\
\text { much effort at all }\end{array}$ & $4=$ takes a lot of effort \\
\hline Taste & $\begin{array}{l}\text { How much do you like or dislike the } \\
\text { taste of filtered water? }\end{array}$ & $-4=\mathrm{I}$ dislike it very much & $4=I$ like it very much \\
\hline Affect & $\begin{array}{l}\text { How much do you like or dislike consuming } \\
\text { filtered water? }\end{array}$ & $-4=\mathrm{I}$ dislike it very much & $4=I$ like it very much \\
\hline Costs & $\begin{array}{l}\text { What to you think about the price of } 120 \text { Birr } \\
\text { for a refill of the filter media? }\end{array}$ & $-4=$ much too cheap & $4=$ much too expensive \\
\hline Descriptive norm & $\begin{array}{l}\text { How many of your neighbors you know } \\
\text { who have a F-removal filter? }\end{array}$ & $0=($ almost nobody $)$ & $4=($ almost $)$ all \\
\hline Subjective norm & Most of my neighbors think I should use the filter. & $-4=\mathrm{I}$ strongly disagree & $4=\mathrm{I}$ strongly agree \\
\hline Personal norm & $\begin{array}{l}\text { I feel a strong personal obligation to } \\
\text { consume filtered water. }\end{array}$ & $-4=\mathrm{I}$ strongly disagree & $4=\mathrm{I}$ strongly agree \\
\hline Status norm & $\begin{array}{l}\text { How proud or ashamed are you to offer } \\
\text { filtered water to your guests? }\end{array}$ & $-2=$ very ashamed & $2=$ very proud \\
\hline $\begin{array}{l}\text { PBC } \\
\quad \text { (filter capacity) }\end{array}$ & $\begin{array}{l}\text { How often do you need more water for drinking and } \\
\text { cooking than is available from the filter? }\end{array}$ & $0=($ almost $)$ always & $4=($ almost $)$ never \\
\hline Self-efficacy & $\begin{array}{l}\text { How confident are you that you will be able to use } \\
\text { the filter regularly in the next month? }\end{array}$ & $0=$ not confident at all & $4=$ very confident \\
\hline Commitment & Do you feel committed to use the filter? & $0=$ not committed at all & $4=$ very much committed \\
\hline Perceived habit & $\begin{array}{l}\text { How much do you feel that you fill the filter as } \\
\text { a matter of habit? Filling the filter is... }\end{array}$ & $0=$ not at all a habit & $5=$ a very strong habit \\
\hline Automaticity & $\begin{array}{l}\text { I fill the filter automatically without thinking } \\
\text { much about it. }\end{array}$ & $-4=\mathrm{I}$ strongly disagree & $4=\mathrm{I}$ strongly agree \\
\hline Remembering & $\begin{array}{l}\text { How difficult is it to remember filling } \\
\text { the filter with water? }\end{array}$ & $0=$ very difficult & $4=$ not difficult at all \\
\hline
\end{tabular}

${ }^{\mathrm{a}} 1$ Ethiopian Birr $=6$ US cents (exchange rate on the 13.6.2011)

a good habit and they easily remembered to use the filter. Automaticity reached a mean of 1.91 , indicating that the beneficiaries did not quite automatically fill the filter. However, the relatively high standard deviation reflects that this is not the case for all users (see Table 3).

To evaluate the main factors that predict fluoride-free water consumption, a binary logistic regression was carried out (see Table 4). The enter method was used to include all hypothesized behavior determinants. Because the dependent variable is dichotomous, a logistic regression was used as the method. The regression results show which factors determined the consumption of only filtered water or the consumption of additional untreated water.

Outlier analysis showed the necessity of excluding four cases (all cases with residuals exceeding more than 3 SDs) from the regression sample, resulting in a total sample size of 156. These outliers were not due to data-entry error and, therefore, could potentially bias the results. The self-efficacy factor showed, after preliminary calculation, a high variance inflation factor (VIF) value, which indicates collinearity with other predictors in the regression (Fox and Monette 1992). A correlation analysis revealed a high correlation between selfefficacy and perceived habit $(r=.54)$. Thus, self-efficacy was excluded from the final regression analysis.

Five variables contributed significantly in predicting the probability of consuming only filtered water. A positive perceived taste of filtered water increased the likelihood of drinking and cooking $100 \%$ with water from the filter. The perceived costs of filter material influenced consumption of only treated water. The more people perceive filter media as 
Table 3 Means, standard deviations of dependent and independent variables, and Cronbach's alpha for scales

\begin{tabular}{|c|c|c|c|c|c|c|}
\hline \multirow{2}{*}{$\begin{array}{l}\text { Behavior } \\
\text { Risk beliefs }\end{array}$} & \multirow{2}{*}{$\begin{array}{l}\begin{array}{l}\text { Variable } \\
\text { Consumption type }^{\mathrm{a}}\end{array} \\
\text { Vulnerability }\end{array}$} & \multirow{2}{*}{$\begin{array}{l}n \\
160 \\
160\end{array}$} & \multicolumn{2}{|c|}{$\begin{array}{l}\text { Range } M \\
\text { Binary variable }\end{array}$} & \multirow{2}{*}{$\begin{array}{l}\mathrm{SD} \\
1.23\end{array}$} & \multirow{2}{*}{$\begin{array}{l}\alpha \\
- \\
.93\end{array}$} \\
\hline & & & $-2-2$ & -0.21 & & \\
\hline & Severity & 160 & $0-4$ & 3.62 & 0.45 & .80 \\
\hline & Health knowledge & 158 & $0-5$ & 2.96 & 1.18 & \\
\hline \multirow[t]{4}{*}{ Attitudinal beliefs } & Time and effort & 160 & $0-4$ & 2.84 & 1.17 & .56 \\
\hline & Taste & 160 & $-4-4$ & 3.66 & 0.69 & - \\
\hline & Affective belief & 160 & $-4-4$ & 3.97 & 0.28 & .76 \\
\hline & Costs & 160 & $-4 \mathrm{v} 4$ & 0.43 & 2.29 & - \\
\hline \multirow[t]{4}{*}{ Normative beliefs } & Descriptive norm & 160 & $0-4$ & 1.60 & 0.75 & .74 \\
\hline & Subjective norm & 160 & $-4-4$ & 3.26 & 0.89 & .84 \\
\hline & Personal norm & 160 & $-4-4$ & 3.73 & 0.37 & .71 \\
\hline & Status norm & 159 & $-2-2$ & 1.40 & 1.13 & - \\
\hline \multirow[t]{2}{*}{ Ability beliefs } & PBC (filter capacity) & 159 & $0-4$ & 2.84 & 1.40 & - \\
\hline & Self-efficacy & 160 & $0-4$ & 3.69 & 0.40 & .76 \\
\hline \multirow[t]{4}{*}{ Maintenance beliefs } & Commitment & 160 & $0-4$ & 3.72 & 0.52 & .79 \\
\hline & Perceived habit & 160 & $0-5$ & 3.53 & 0.55 & - \\
\hline & Automaticity & 160 & $-4-4$ & 1.91 & 2.93 & - \\
\hline & Remembering & 160 & $0-4$ & 3.71 & 0.84 & - \\
\hline
\end{tabular}

Note. No attempt was made to reconstruct missing data. Theoretical range is displayed. For factors with multiple items, Cronbach's alpha $(\alpha)$ for scale reliability is indicated

${ }^{\mathrm{a} C}$ Consumption type $(1=$ only consuming filtered water,

$0=$ still consuming raw water) filter increased the chance of consuming filtered water. None of the risk belief factors showed significant influence in the regression.

In total, there was a good model fit (Nagelkerke= $67.9 \%$ ), and $88.8 \%$ of the consumption types were correctly classified. The calculated VIF values showed no evidence of high multicollinearity; thus, all values are between 1.12

Table 4 Logistic regression analysis for variables predicting consumption of filtered water

\begin{tabular}{|c|c|c|c|c|c|c|}
\hline & Variable & $B$ & SE $B$ & $\operatorname{Exp}(B)$ & $p$ & $\begin{array}{l}\mathrm{Cl}(95 \%) \\
\text { for } \operatorname{Exp}(B)\end{array}$ \\
\hline \multirow[t]{3}{*}{ Risk beliefs } & Vulnerability & 0.134 & 0.269 & 1.143 & 0.618 & $(0.675,1.936)$ \\
\hline & Severity & -0.125 & 0.948 & 0.882 & 0.895 & $(0.138,5.652)$ \\
\hline & Health knowledge & -.382 & 0.334 & 0.683 & 0.254 & $(0.354,1.315)$ \\
\hline \multirow[t]{4}{*}{ Attitudinal beliefs } & Time and effort & .156 & 0.286 & 1.169 & 0.586 & $(0.668,2.045)$ \\
\hline & Taste & 1.155 & 0.467 & 3.174 & 0.013 & $(1.271,7.926)$ \\
\hline & Affect & -0.212 & 1.034 & 0.809 & 0.838 & $(0.107,6.135)$ \\
\hline & Costs & 0.332 & 0.150 & 0.717 & 0.026 & $(0.535,0.962)$ \\
\hline \multirow[t]{3}{*}{ Normative beliefs } & Descriptive norm & -0.037 & 0.478 & 0.963 & 0.938 & $(0.378,2.456)$ \\
\hline & Subjective norm & -.568 & 0.455 & 0.567 & 0.212 & $(0.232,1.382)$ \\
\hline & Status norm & 2.222 & 0.518 & 9.228 & 0.000 & $(3.341,25.491)$ \\
\hline Ability beliefs & PBC (filter capacity) & 1.205 & 0.319 & 3.336 & 0.000 & $(1.787,6.229)$ \\
\hline \multirow[t]{4}{*}{ Maintenance beliefs } & Commitment & 0.455 & 0.509 & 1.577 & 0.371 & $(0.582,4.273)$ \\
\hline & Perceived habit & 1.912 & 0.650 & 6.766 & 0.003 & $(1.893,24.183)$ \\
\hline & Automaticity & -0.093 & 0.125 & 0.911 & 0.456 & $(0.713,1.164)$ \\
\hline & Remembering & -0.167 & 0.411 & 0.846 & 0.684 & $(0.378,1.893)$ \\
\hline Constant & & -14.06 & 4.641 & 0.000 & 0.002 & \\
\hline
\end{tabular}

Note. Nagelkerke $R^{2}=.679$, LR- $\chi^{2}=91.446$ with $d f=15(p<.000), n=156$ (due to outlier removal); a forced entry method was used for the calculation 
and 1.68. Furthermore, standardized residuals were normally distributed in both regressions. In addition, homoscedasticity in the calculated regression was ensured.

\section{Discussion}

The purpose of the present research was to reveal substantial social psychological determinants of consuming fluoride-free water deriving from relevant factors of various behavior change theories. One goal was to gain knowledge about how using the filter and filtered water is perceived, what people's risk beliefs were, and how users estimate social impacts. It was of particular interest to identify factors that influence users who consume only filtered water in order to derive interventions to decrease the number of raw water consumers.

In general, filter owners consume a respective amount of treated water within their daily requirement. This applies to drinking filtered water as well as to cooking with filtered water. The fact that filter users paid a contribution for the filter and obtained the filter only a short time before the survey was conducted may offer an explanation for this finding.

Even though all villages have access only to highly contaminated water, people do not feel vulnerable to dental or skeletal fluorosis. Also, the hypothesized impact of risk beliefs on the probability of consuming filtered water could not be confirmed. However, Gerrard et al. (1996) pointed out that estimating the likelihood of contracting a certain disease seems to depend on various socio-demographical and situational factors. Moreover, in the project area, deep tube wells and boreholes for fetching groundwater were installed only around 10 years ago. Before that, mainly surface water was consumed, which had lower fluoride concentration than groundwater. This circumstance implies that the older generation of villagers was not exposed to dental fluorosis during their childhood and therefore might feel less vulnerable to skeletal fluorosis.

Attitudinal beliefs toward filtering were in general very positive. The perceived cost of filter media is the only attitudinal belief, which is neither high nor low, but on average is perceived as valid. This is not surprising taking into account that the average monthly income in the rural area is low. Further, it was expected that filter users were influenced by attitudinal beliefs. The better tasting the treated water is perceived to be, the more probable the likelihood is that filtered water will be consumed exclusively. Before filter distribution, people expressed their concerns about bone char media changing the taste of treated water. Learning that their assumptions were unverified probably surprised the participants and led to a highly positive taste perception. Interestingly, the costs variable operated in an inverse relationship than what had been expected. The significant effect indicates that the more expensive the filter material is perceived to be, the more likely households will consume filtered water exclusively. In other words, the more the filter material is evaluated as expensive, the more valuable they might become and the more likely filter users will consume only filtered water. This finding is consistent with Cialdini's (2001) assumed stereotype of "expensive products must be good," which works as a judgmental heuristic. The positive role of price was also examined by marketing researchers such as Lichtenstein et al. (1993), who stated that the high price of a product can be perceived as positive because the consumer relates the high price to higher quality.

Overall, normative beliefs were positive. Neighbors, friends, and significant others seemed mostly to approve of filter usage, probably because of the health effect. However, neither descriptive nor subjective norms showed significant influence on behavior. Not finding a positive influence is reasonable, taking into account that using a household filter is a private rather than public displayed behavior. Filter owners feel proud to present their treated water to guests. In addition, the perceived personal obligation is mainly high among users. Having purchased something valuable and now possessing an expensive new device might be drivers for feeling proud and obligated to use the filter. The status norm, the feeling of pride in offering filtered water to guests, showed the strongest positive impact. Thus, the more people feel proud offering filtered water to guests, the more probable that they will consume only filtered water. This finding can be explained by the importance of visiting in the Ethiopian culture. Being able to serve healthy water to neighbors and friends visiting seems to be meaningful and thus influences filter use.

Furthermore, filter users perceive themselves as capable of using the filter regularly even though many users believed the filter bucket was too small to produce enough water for their whole family. Perceived behavior control showed a strong positive influence on filter use. The positive impact indicates that the more users feel they have enough water available, the more likely that they will consume exclusively filtered water. The behavior itself, filling the filter and consuming filtered water, seems not to be considered difficult. By contrast, producing enough filtered water for the whole family, which means filling the filter at the right moments when filtered water is needed, requires more effort.

Finally, maintenance beliefs show that people feel very committed to using their filter, and perceive filling the filter as a matter of habit, even though the automaticity of filling could increase. Remembering to fill the filter was perceived as easy. Considering that the action of filling is easy to 
perform and that the big colorful filter bucket on its own acts as a reminder, these results are not unexpected. The perceived habit of filling the filter seems to be a strong predictor of the probability of filter use. The more the filter refilling is perceived as a habit, the more likely that new users will consume only filtered water. Findings of recent research on use of solar water disinfection (SODIS) showed that habit is an important variable for explaining the increase of SODIS use (Kraemer and Mosler 2010). However, filtering the water is a relatively easy activity to perform, and people may quickly develop a perceived habit if they fill the filter once a day (e.g., every morning). Therefore, the influence of perceived habit on new users' filter use does not indicate that users fill the filter sufficiently per day to cover their total water consumption. Probably, filling the filter more than once may become more difficult in the daily routine and is more coherent with perceived automaticity of filling the filter.

Limitations of the study and future research

Some limitations of the present study are noteworthy. One limitation is the self-reported data and the interviewers' questions that may evoke a social bias. During the workshop, the interviewers were sensitized to that problem and the importance of the introduction before starting the interview. In the introduction, the interviewers pointed out that participants should answer in their interest as honestly as possible. However, another type of survey such as a paper-and-pencil investigation would have been impossible due to the high illiteracy rate in the population, and observed behavior monitoring would have been very difficult and highly reactive.

Additionally, the behavior measurement itself needs improvement. It seems appropriate in future research to focus on how much water is filtered per day as the dependent variable, because it is assumed that water, which was filtered is also consumed sooner or later. With this variable, linear instead of logistic regressions could be calculated with the advantage that the results will be more conclusive and more meaningful to interpret. However, various studies about health behavior implementing self-reported data indicate its significance for behavior performance (e.g., Holm et al. 2003; Verplanken and Orbell 2003).

Before discussing the implications for practice gained from these results it has to be mentioned that the following findings might have been different for other Ethiopian populations in other areas. Therefore, a follow-up study in different areas would be advisable.

Implications for practice

Bone char filtration seems to be widely accepted among the household filter users, even though most of them know that the filter material is a processed animal product. Hence, a defluoridation technique was found that is simple, effective, inexpensive, and socially accepted by the Ethiopian population.

Regarding the implementation of household filters, the advantage of bigger buckets with more storage capacity should be considered due to the result that the probability of consuming only filtered water increases if people feel that there is enough water available from the filter. Furthermore, it is favorable to set a contribution price for new filters as well as for the filter material, which is perceived as costly and therefore considered as something valuable. Further, inconsistent filter filling should be a focus. New users should be induced to fill the filter more than once or twice a day, depending on the number of family members, by giving them rules of thumb (e.g., filling the filter once per day per person in household). A positive perceived taste of treated water is an important factor enhancing filter use. Therefore, before new filter technologies are implemented, filter media should be tested regarding taste. Fortunately, bone char material does not seem to change the taste of raw water; moreover, after filtering, the water seems very tasty. The fact of an overall positive perceived taste can be used for promotion within the community for gaining new filter users.

Intervention strategies to maintain or improve filter use should target perceived habit of filtering. Prompts or a daily routine planning together with promoters could be effective intervention strategies for forming a habit in terms of an automatic behavior performance of filling the filter to have as much water as needed for the entire household. Prompts are external memory aids that act as situational cue stimuli and lead to habit formation (Dahlstrand and Biel 1997). Effective tools for daily routine planning are, for example, implementation intentions, which help people perform a specific behavior by making concrete plans of actions that specify how, where, and when actions should be performed to achieve an intended goal (Gollwitzer 1999). When the filter should be filled and how to incorporate the consumption of filtered water in daily routines should be discussed with the filter users.

To further enhance treated water consumption, the status norm should be taken into account. A public commitment intervention could target the importance of presenting filtered water to guests. Individuals communicate in public to perform a certain behavior (Mosler and Tobias 2007). One possibility is to provide filter users with a clear noticeable sign (e.g., a flag on the rooftop, a poster on the front door). The pride of possessing a filter and being able to provide guests with healthy water is hence visible to the community. Further, the public commitment enhances a descriptive norm for filter use and at the same time evokes a social pressure to do what they communicated in public 
for themselves. Various studies showed the effectiveness of this intervention technique in changing behavior (e.g., De Young 1993; Dwyer et al. 1993).

This study reveals important insights into the usage of a newly implemented household water treatment system. Intervention strategies to further enhance and develop habitual usage of fluoride removal filters can be developed and implemented to increase safe water consumption and prevent dental and skeletal fluorosis.

Acknowledgements This study is part of the Water Resource Quality (WRQ) project at EAWAG. Most of all, we would like to extend thanks to Esayas Samuel, Tesfaye Edosa, and Feyisa Lemma from the Oromia Self Help Organization (OSHO)for their professional input, valuable contribution, and great collaboration during the field work. Further, we want to name the Swiss National Science Foundation (SNF) and the Swiss Agency for Development and Cooperation (DEZA) as the project's financial support. Finally, our acknowledgment also goes to the Swiss Interchurch Aid (HEKS), which provided the project with the household filters.

Conflicts of interest The authors declare that they have no conflict of interest.

\section{References}

Ajzen I (1991) The theory of planned behavior. Organ Behav Hum Dec Proc 50:179-211

Amini M, Mueller K, Abbaspour KC, Möller KN, Sarr M, Johnson CA (2008) Statistical modeling of global geogenic fluoride contamination in groundwaters. Envirol Sci Technol 42 (10):3662-3668

Armitage CJ (2005) Can the theory of planned behavior predict the maintenance of physical activity? Health Psychol 24:235-245F

Bandura A (2004) Health promotion by social cognitive means. Health Educ Behav 31:143-164

Becker MH, Maiman LA, Kirscht JP, Haefner DP, Drachman RH (1977) The health belief model and prediction of dietary compliance: a field experiment. J Health Soc Behav 18:348-366

Cialdini RB (2001) Influence: science and practice, 4th edn. Allyn and Bacon, Boston

Cialdini RB, Reno RR, Kallgren CA (1990) A focus theory of normative conduct: recycling the concept of norms to reduce littering in public places. J Pers Soc Psychol 58:1015-1026

Conner M, Armitage CJ (1998) Extending the theory of planned behavior: a review and avenues of further research. J Appl Soc Psychol 28:1429-1464

Dahlstrand U, Biel A (1997) Pro-environmental habits: propensity levels in behavioral change. J Appl Soc Psychol 27:588-601

De Young R (1993) Changing behavior and making it stick: the conceptualization and management of conservation behavior. Environ Behav 25:485-505

Dwyer WO, Leeming FC, Cobern MK, Porter BE, Jackson JM (1993) Critical review of behavioral interventions to preserve the environment: research since 1980. Environ Behav 25:275-321

Fox J, Monette G (1992) Generalized collinearity diagnostics. J Am Stat Ass 87:178-183

Gerrard M, Gibbons FX, Bushman BJ (1996) Relation between perceived vulnerability to HIV and precautionary sexual behavior. Psychol Bull 119:390-409
Gollwitzer PM (1999) Implementation intentions: strong effects of simple plans. Am Psychol 54:493-503

Harland P, Staats H, Wilke HAM (2007) Situational and personality factors as direct or personal norm mediated predictors of proenvironmental behavior: questions derived from norm-activation theory. Basic Appl Soc Psychol 29:323-334

Heckhausen H (1991) Motivation and action. Springer Verlag, Berlin

Heri S, Mosler HJ (2008) Factors affecting the diffusion of solar water disinfection: a field study in Bolivia. Health Educ Behav 35:541560

Holm K, Kremers SPJ, de Vries H (2003) Why do Danish adolescents take up smoking? Eur J Public Health 13:67-74

Kloos H, Tekle-Haimanot R (1999) Distribution of fluoride and fluorosis in Ethiopia and prospects for control. Trop Med Int Health 4:355-364

Kraemer SM, Mosler HJ (2010) Persuasion factors influencing the decision to use sustainable household water treatment. Int $\mathrm{J}$ Environ Health Res 20:61-79

Krebs R (2002) Anleitung zur Herstellung von MC-Fragen und MCPrüfungen [Instructions for preparing $\mathrm{MC}$-questions and $\mathrm{MC}$ exams]. http://www.fnl.ch/LOBs/LOs_Public/MC Anleitung.pdf. Cited 6 March 2010

Lichtenstein DR, Ridgway NM, Netemeyer RG (1993) Price perception and consumer shopping behavior: a field study. J Marketing Res 30:234-245

Maddux JE, Rogers RW (1983) Protection motivation and selfefficacy: a revised theory of fear appeals and attitude change. $J$ Exp Soc Psychol 19:469-479

Malde MK, Scheidegger R, Julshamn K, Bader HP (2011) Substance flow analysis: a case study of fluoride exposure through food and beverages in young children living in Ethiopia. Environ Health Perspect 119:579-584

Mosler HJ, Tobias R (2007) Umweltpsychologische Interventionsformen neu gedacht [Environmental psychological forms of interventions re-thought]. Umweltpsychologie 11:35-54

Mosler HJ, Blöchliger OR, Inauen J (2010) Personal, social, and situational factors influencing the consumption of drinking water from arsenic-safe deep tubewells in Bangladesh. J Environ Manage 91:1316-1323

Orbell S, Blair C, Sherlock K, Conner M (2001) The theory of planned behavior and ecstasy use: roles for habit and perceived control over taking versus obtaining substances. J Appl Soc Psychol 31:31-47

Orbell S, Lidierth CJ, Geeraert N, Uller C, Uskul AK, Kyriakaki M (2009) Social-cognitive beliefs, alcohol, and tobacco use: a prospective community study of change following a ban on smoking in public places. Health Psychol 28:753-661

Park HS, Smith SW (2007) Distinctivness and influence of subjective norms, personal descriptive and injunctive norms, and societal descriptive and injunctive norms on behavioral intent: a case of two behaviors critical to organ donation. Hum Comm Res $33: 194-218$

Prochaska JO, DiClemente CC (1982) Transtheoretical therapy: toward a more integrative model of change. Psychother-Theor Res 19:276-288

Schwartz SH (1977) Normative influence on altruism. In: Berkowitz L (ed) Advances in experimental social psychology. Academic, New York, pp 221-279

Smith JR, Terry DJ, Manstead ASR, Louis WR, Kotterman D, Wolfs J (2008) The attitude-behavior relationship in consumer conduct: the role of norms, past behavior, and self-identity. J Soc Psychol 148:311-333

Tekle-Haimanot R (2005) Study of fluoride and fluorosis in Ethiopia with recommendations on appropriate defluoridation technologies. Consultancy report, UNICEF-Ethiopia, University of Addis Ababa, Faculty of Medicine, Ethiopia 
Tekle-Haimanot R, Melaku Z, Kloos H, Reimann C, Fantaye W, Zerihun L, Bjorvatn K (2006) The geographic distribution of fluoride in surface and groundwater in Ethiopia with an emphasis on the Rift Valley. Sci Total Environ 367:182-190

Tobias R (2009) Changing behavior by memory aids: a social psychological model of prospective memory and habit development tested with dynamic field data. Psychol Rev 116:408-438
Verplanken B, Aarts H (1999) Habit, attitude, and planned behaviour: Is habit an empty construct or an interesting case of goal-directed automaticity? Eur Rev Soc Psychol 10:101-134

Verplanken B, Orbell S (2003) Reflections on past behavior: a selfreport index of habit strength. J Appl Soc Psychol 33:1313-1330

Wondwossen F, Åstrøm AN, Bjorvatn K, Bårdsen A (2006) Sociodemographic and behavioural correlates of severe dental fluorosis. Int J Paediatr Dent 16:95-103 